\title{
NOTAS
}

\section{Crédito agrario y agricultura familiar en Brasil. Análisis de la morosidad en la aplicación del Programa nacional de fortalecimiento de la agricultura nacional'}

\section{Flávio Sacco dos Anjos² y Nádia Velleda Caldas ${ }^{3}$}

Palabras clave: agricultura familiar; insolvencia, financiación pública

Key words: family farming, insolvency, public financing

Mots clés: Agriculture familiale, Insolvabilité, Financement publique.

\section{Introducción}

La financiación del sector agrario es un tema de gran importancia en las sociedades contemporáneas, suscitando polémica y controversia en las instancias políticas y entre los grupos sociales implicados. El despoblamiento del campo, los problemas medioambientales, los excedentes agrarios o la seguridad alimentaria no son hechos aislados y desconectados entre sí, sino que cada uno de ellos pone al descubierto las entrañas de una crisis profunda que no puede ser interpretada

\footnotetext{
1 Este trabajo ha sido desarrollado gracias a la financiación del "Conselho Nacional de Pesquisa e Desenvolvimento Tecnológico" (CNPQ) y de la "Coordenação de Aperfeiçoamento de Pessoal de Nível Superior" (CAPES), mediante el programa de cooperación e intercambio con España (Programa Capes - DGU).

2 Universidade Federal de Pelotas, Faculdade de Agronomía "Eliseu Maciel".

${ }^{3}$ Doctoranda del Programa de Postgrado sobre Sistemas de Producción en la Agricultura Familiar.
} 
sin relacionarla con los procesos más amplios que afectan a la agricultura y al conjunto de la sociedad.

El tema de la financiación agraria es uno de esos temas que se sitúan en el centro del escenario que afecta hoy a la agricultura, siendo por ello objeto de interés por parte de los analistas económicos y sociales. Al analizarlo se está valorando hasta qué punto el modelo de desarrollo adoptado en los años 60-70 en los países industrializados (en el que los programas de crédito a los agricultores fueron un elemento clave de la política agraria) es hoy un camino apropiado para avanzar en el proceso de modernización de los países en desarrollo.

En el caso europeo, como bien subrayó Hervieu (1996), los problemas han sido generados por una política agraria (PAC) "víctima de su propio éxito", una expresión que habría que interpretar como resultado de la siguiente paradoja: la implantación de la PAC fue, sin duda, responsable de impulsar un incremento exponencial de la producción agraria contribuyendo al autoabastecimiento de la población europea, pero, al mismo tiempo, la PAC provocó también importantes externalidades negativas, sobradamente conocidas.

Los desafíos que debe superar hoy el mundo agrícola europeo son de gran envergadura. Uno de ellos, como bien destacó Ramos Real y Delgado Serrano (2002), radica en la "crisis de legitimidad" que padece la PAC y que, desde una perspectiva no europea, afecta a las políticas agrarias de los diversos países del planeta que toman como referencia lo que se hace en la Unión Europea. La excesiva concentración del gasto de la PAC en las grandes explotaciones agrarias, y el escaso volumen de ayudas destinadas a los agricultores con explotaciones menos competitivas, así como a las zonas desfavorecidas y al desarrollo rural, pueden ser analizados como aspectos que activan la mencionada crisis de legitimidad de la política agraria europea.

Para el hilo argumental de este artículo es importante destacar que el reconocimiento de esas distorsiones en la política europea suscitó un interesante debate en Brasil, debate que permitió generar una nueva y singular política pública -el Programa Nacional de Fortalecimiento de la Agricultura Familiar (en adelante, PRONAF)- destinada a apoyar a las explotaciones de carácter familiar y a fomentar el desarrollo de las áreas rurales.

Sin embargo, como veremos a continuación, la implementación de dicho programa ha puesto de manifiesto ciertas contradicciones que merecen ser analizadas. Una de ellas radica en el reconocimiento de que la notable extensión del PRONAF, 
tanto desde la perspectiva del número de agricultores beneficiarios, como del volumen de los recursos asignados, no ha ido acompañada de un programa de mejora de las infraestructuras (transporte, comercialización, asistencia técnica,...), lo que ha sido uno de los factores decisivos de sus insatisfactorios resultados en algunas regiones brasileñas, donde hay indicios ciertos de que aumenta el nivel de incumplimiento en los contratos del programa y, en consecuencia, el nivel de morosidad de los agricultores beneficiarios.

El objetivo de este artículo es analizar el proceso de implementación del PRONAF a partir de datos del Ministerio brasileño de Hacienda (2008) y de otras fuentes de información. Algunas preguntas orientaron la investigación, a saber: ¿̇cuáles son los sectores de la agricultura familiar brasileña que presentan los más altos niveles de incumplimiento en la devolución de los créditos contraídos en el marco del programa?; ¿ ès la expansión del PRONAF hacia las regiones más deprimidas de Brasil una de las razones del incremento de las tasas de incumplimiento de los contratos?; ìhay diferencias en el grado de endeudamiento entre, de un lado, las familias asentadas en los proyectos de reforma agrariay, de otro, los demás sectores de la agricultura familiar, comparativamente más consolidados que aquéllos?

En el primer apartado de este artículo se ofrece una breve aproximación al contexto histórico y social en el que surge el PRONAF, analizándose en el segundo apartado la importancia y evolución reciente de dicho programa. En el tercer apartado se expone los elementos del debate en torno al tema del incumplimiento en los contratos y sus posibles causas explicativas. Finalmente, se presentan algunas conclusiones del estudio.

\section{La agricultura familiar en Brasil y la creación del PRONAF}

La década de los noventa del pasado siglo XX coincide con un conjunto de grandes transformaciones en la sociedad y en la agricultura brasileña. Consiste en un período de apertura de la economía, con la profundización del proceso de integración regional (consolidación del Mercado Común del Cono Sur, Mercosur), con los cambios legislativos resultantes de la promulgación de la nueva Constitución (1988) y, sobre todo, con las amplias movilizaciones protagonizadas por los movimientos sociales en torno a la ampliación del acceso a la tierra y a la financiación pública de las actividades agrarias.

En el contexto de esos cambios surge, en 1994, durante el gobierno del Presidente Itamar Franco, el Programa de Valorización de la Pequeña Producción 
Rural (PROVAP), que básicamente se financiaba, como afirma Belik (2000), con los créditos concedidos por el Banco Nacional de Desarrollo Económico y Social (BNDES). Hasta entonces, Brasil nunca había contado con un programa nacional de apoyo público al sector de la agricultura familiar, un sector que, en los manuales del crédito agrario, figuraba como un colectivo formado por una miríada de de micro o mini productores.

En esa misma década, casi simultáneamente a la aparición del PROVAP, aparecen algunos estudios (Pereira Bergamasco, 1903; FAO/INCRA, 1994) que mostraban la importancia de la producción familiar en la agricultura brasileña, no solamente desde el prisma de su contribución al abastecimiento nacional de alimentos (leche, huevos, hortalizas, frutas, ...), sino también en el ámbito de las exportaciones (soja, aves, porcino y tabaco) hacia Europa, Asia y demás continentes.

Como señaló Leite (2004), la publicación de esos estudios significó un cambio radical en el modo de percibir la función de la pequeña agricultura familiar en la economía brasileña, rompiéndose la asociación peyorativa que, hasta entonces, lo vinculaba con la producción de subsistencia y que explicaba el hecho de que este sector fuera tratado sólo con políticas de carácter social y compensatorio. Como resultado de dicho reconocimiento surge, en 1995, la idea de crear el "Programa Nacional de Fortalecimiento de la Agricultura Familiar" (PRONAF), un programa previsto inicialmente para financiar, mediante la concesión de créditos a los agricultores, los costes de la campaña agrícola y ganadera, que luego se ampliarían a la financiación de las inversiones en las explotaciones agrarias.

La regulación del PRONAF (Bittencourt, 2003: 101) se produce a través del Decreto-ley $n^{\circ} 1.946 / 1996$, en el que se establece que la población objeto del programa son los titulares de explotaciones agrarias con hasta cuatro "módulos fiscales" 4 , que residan en la explotación, que empleen hasta dos trabajadores asalariados con carácter permanente y que, además, generen el $80 \%$ de la renta en su propia explotación.

No obstante, a lo largo de los años noventa, se introdujeron cambios significativos en el programa, destacando el que se produce a nivel político con el traspaso de

${ }^{4}$ El "módulo fiscal" es definido en la legislación agraria brasileña (Ley n 4504 de 30/11/1964 o Estatuto de la Tierra) como el equivalente a una superficie agraria (en hectáreas) capaz de garantizar la supervivencia de una familia rural. Su extensión es variable en función de la región del país y según el tipo de explotación (intensiva o extensiva). En los Estados del Sur de Brasil, un "módulo fiscal" puede equivaler a 15 hectáreas, mientras que en los del Norte puede alcanzar las 80 hectáreas, debido al carácter más extensivo de las actividades agrarias o a la precariedad estructural. 
las competencias relacionadas con el PRONAF desde el Ministerio de la Agricultura, Pesca y Alimentación al recién creado Ministerio del Desarrollo Agrario. En la nueva distribución de competencias, el primero se hacía cargo de las clásicas políticas agrarias de fomento de la gran explotación, mientras que el Ministerio de Desarrollo Agrario se orientaba a la puesta en marcha de políticas de tipo estructural, como la reforma agraria o la erradicación de la pobreza en el medio rural, asumiendo el apoyo a las diversas formas en las que se expresaba la agricultura familiar brasileña.

El PRONAF se estructuraba en torno a cuatro grandes líneas de crédito $(A, B, C$ y $D)$ destinadas a los agricultores familiares. La línea $A$, que sustituía al antiguo PROCERA (Programa de Crédito Especial para la Reforma Agraria), contemplaba la financiación de los costes de producción de la campaña agrícola y ganadera y la financiación de las inversiones realizadas por las familias asentadas en las áreas de la reforma agraria o en predios rurales adquiridos por compra directa financiada con fondos públicos ${ }^{5}$. La línea $B$ tenía por objetivo apoyar a las familias rurales con rentas anuales inferiores a 4.000 reales (por lo general, comunidades de origen afroamericano, poblaciones indígenas, grupos de pescadores artesanales,...). Las líneas $C$ y $D$ se orientaban hacia las familias rurales con rentas algo más altas en términos comparativos (entre 4.000 y 50.000 reales) ${ }^{6}$.

La lógica del programa respondía al objetivo de promover la integración en el mercado de los campesinos más pobres y, al mismo tiempo, de consolidar una base amplia de explotaciones agrarias de tipo familiar en los distintos puntos de la geografía brasileña. Sin embargo, en el año agrícola 2003-2004 surgiría una cuarta línea de financiación (la llamada línea E) destinada a los agricultores familiares con niveles de renta bruta anual comprendida entre los 40.000 y los 60.000 reales. Esos cambios suponían una ampliación considerable de los créditos destinados a un sector de la agricultura brasileña tradicionalmente excluido de los fondos públicos de financiación. Si bien, tras la aprobación del PRONAF, la agricultura de base patronal o empresarial seguiría siendo, como antaño, la principal

${ }^{5}$ Eran los llamados "Programas de Crédito Fundiario", destinados a favorecer el acceso de los campesinos sin tierra a la propiedad agraria, con fondos públicos del Estado brasileño y con el apoyo del Banco Mundial. Estos programas seguían el modelo ya implantado en diversos países del mundo (Malaui, Colombia, Honduras, México o Zimbabue). Sobre este tema, puede verse Sacco dos Anjos et al. (2007).

${ }^{6}$ La línea $\mathrm{C}$ contemplaba como beneficiarios a familias rurales con ingresos brutos anuales comprendidos entre 4.000 y 18.000 reales, mientras la línea $D$ estaba destinada a las que poseían rentas anuales entre 18.000 y 50.000 reales. 
beneficiaria de la mayor parte de los créditos públicos (aproximadamente, 60 mil millones de reales, es decir, seis veces más de lo que se destinaba a la agricultura familiar), lo cierto es que con dicho programa se produce una verdadera democratización de la política de financiación agraria al ampliarse la base de beneficiarios. Dada la situación de precariedad estructural y de permanente inestabilidad de los campesinos y de los agricultores de tipo familiar ${ }^{7}$, cabe considerar la aprobación del PRONAF como un auténtico punto de inflexión en la reciente historia de la política agraria brasileña (Baudel Wanderley, 1999).

No obstante, la reciente publicación por el Ministerio de Hacienda del informe sobre el nivel de endeudamiento de los agricultores familiares (mostrando un considerable aumento del mismo y un incremento del grado de insolvencia de este colectivo) ha provocado un importante debate sobre los impactos reales del PRONAF y sobre su verdadera contribución al desarrollo económico y social del medio rural brasileño. No es posible reproducir en el espacio limitado de este artículo los argumentos esgrimidos en el debate sobre los efectos del PRONAF, dada la complejidad y amplitud de un programa que ha alcanzado casi 2 millones de contratos de financiación en todo el territorio de un país tan inmenso y variado como Brasil. Algunas posiciones señalan que el PRONAF no es más que un programa de crédito cuyo objetivo ha estado circunscrito a la ampliación del número de beneficiarios de recursos públicos, habiendo sido muy limitada su capacidad para contribuir al fomento del desarrollo de las áreas rurales brasileñas.

\section{Importancia y evolución del PRONAF}

\section{I. Breve aproximación a la realidad social y económica de Brasil}

Antes de entrar en el análisis de los efectos del PRONAF, y dado que el artículo se dirige sobre todo a lectores no brasileños, creo necesario dedicar algunas líneas a exponer la realidad geográfica y socioeconómica de Brasil. En términos

\footnotetext{
7 La distinción entre "campesinos" y "agricultores familiares" es objeto de un acalorado debate en las ciencias sociales brasileñas que no puede reproducirse en el limitado espacio de este artículo. No obstante, para el hilo argumental de este trabajo cabe señalar que los "agricultores familiares" son percibidos como los titulares de pequeñas explotaciones agrarias con un elevado nivel de integración en los mercados, mientras que el término "campesino" se utiliza para denominar a los que poseen tierras muy poco integradas en los mercados y dedicadas casi exclusivamente a la subsistencia de la familia.
} 
geográficos, Brasil se divide en cinco grandes regiones: Norte, Nordeste, Sureste, Centro-Oeste y Sur, que abarcan los 26 estados que componen la República Federal brasileña. Aunque esas cinco regiones no constituyen unidades políticoadministrativas autónomas, expresan, sin embargo, la diversidad del territorio brasileño, por lo que es interesante proceder aquí a su descripción. La Región Norte es la más grande, concentrando casi el $45 \%$ de todo el territorio nacional (comprende los estados de Amazonas, Pará, Acre, Rondônia, Roraima, Amapá y Tocantins). La Región Nordeste comprende los estados de Maranhão, Piauí, Ceará, Rio Grande do Norte, Paraíba, Pernambuco, Alagoas, Bahia y Sergipe. A la Región Sureste pertenecen los estados de Minas Gerais, São Paulo, Rio de Janeiro y Espirito Santo, y a la Región Centro-Oeste los de Goiás, Mato Grosso, Mato Grosso do Sul y el Distrito Federal (Brasília, DF). Finalmente, la Región Sur, que es la más pequeña de las cinco regiones brasileñas, comprende los estados de Rio Grande do Sul, Santa Catarina y Paraná.

Tan inmenso territorio refleja no sólo la realidad de un país (Brasil), sino la realidad diversa de muchas áreas llenas de contrastes, como puede ponerse de manifiesto si se compara la inmensa zona que incluye los estados de las regiones Norte y Nordeste con los estados de las regiones Sur y Sureste. Esa enorme diversidad refleja también un elevado nivel de desigualdad social, tal como se expresa en los últimos datos del Indicador del Desarrollo Humano (IDH) elaborado por el Programa de las Naciones Unidas para el Desarrollo (PNUD, 2005).

Así, mientras que en las regiones Sur y Sureste, el IDH alcanza valores superiores a 0,8 , en los estados de las regiones Norte y Nordeste no supera el 0,7 , habiendo algunos estados (como Maranhão y Alagoas) en los que el IDH es muy bajo $(0,68$ y 0,67 respectivamente, cercano al de los países del África subsahariana). El IDH de los estados de la región Centro-Oeste se sitúa en una posición intermedia entre los del eje Sur-Sureste y el eje Norte-Nordeste de Brasil. El bajo nivel de IDH es resultado de diversos factores, entre los que destacan los elevados niveles de desigualdad social y económica en la población y la elevada concentración de los medios de producción (tierra y capital).

\subsection{Efectos económicos y sociales del PRONAF}

La creación del PRONAF debe enmarcarse en el proceso general de democratización que, al comienzo de los años 90, se produce en Brasil tras casi veinte años de dictadura militar. En la década de los 70 y 80 del pasado siglo XX, tiene lugar, bajo gobiernos militares, lo que algunos autores han denominado la 
"modernización conservadora" de la agricultura brasileña (Graziano da Silva, 1982), al entender que si bien se produjeron cambios importantes en los sistemas productivos agrarios (gracias a una mayor mecanización de las explotaciones y al aumento de los insumos agrícolas, como los abonos químicos y las semillas con alto potencial productivo), se mantuvo intacta la secular concentración de la propiedad de la tierra (Sacco dos Anjos, 2001).

La década de los 90 coincide con la implantación del llamado "Plan Real", un programa de estabilización monetaria articulado con una política de ajuste fiscal en la que se produce la retirada del Estado de algunas áreas, transfiriendo a los mercados una serie de competencias, como fue el caso de la liberalización de los precios de los productos agrarios y de los insumos agrícolas. La política de intervención estatal en la agricultura quedó limitada sólo al caso en que hubiese riesgo de un incremento desorbitado de los precios (inflación) que pudiera repercutir en el plan de estabilización monetaria.

Como resultado de todo ello, los agricultores experimentaron un elevado descenso en las rentas agrarias. Los más perjudicados fueron los titulares de explotaciones familiares, debido, sobre todo, a la apertura comercial y a las incidencias climatológicas que afectaron a los estados meridionales en dónde se encontraban en aquellas fechas (años noventa) las zonas más productivas de cereales y oleaginosas de Brasil. Fruto de esos problemas se originaron conflictos por todo el país y grandes manifestaciones de protesta en la capital federal (Brasilia) protagonizadas por los pequeños agricultores y por los campesinos sin tierra, que reivindicaban una solución a la grave crisis que asolaba al medio rural brasileño. Aunque entre las reivindicaciones los problemas de los colonos asentados en las áreas de la reforma agraria eran los más emblemáticos, no puede minimizarse la importancia que tales protestas campesinas tuvieron en la aprobación del PRONAF. De hecho, este programa incluía entre sus objetivos, como se mencionó anteriormente, no sólo conceder créditos a los agricultores de tipo familiar, sino también a los campesinos asentados en las áreas de reforma agraria, un objetivo éste que fue bastante criticado por algunos autores (Domingos Neto, 2004) al considerar muy limitado el volumen de recursos destinado a ese colectivo.

En sus orígenes, el PRONAF fue concebido como un programa destinado a promover el desarrollo del medio rural brasileño y dirigido a los campesinos y los agricultores familiares, pero desde una perspectiva amplia y no centrada exclusivamente en el apoyo a la agricultura. Su objetivo era financiar las actividades agrarias y no agrarias desarrolladas en la explotación por el agricultor y su familia, entendiéndose por estas últimas las actividades relacionadas con el turismo rural, la producción 
artesanal y cualquier otro tipo de servicios que pudieran mejorar la utilización de la mano de obra familiar (BNDES, 2008).

La Figura $\mathrm{n}^{\circ} 1$ muestra el crecimiento del PRONAF en el período comprendido entre los años 1999 y 2007. Se observa un considerable aumento del número de contratos de crédito realizados por los agricultores -tanto en los destinados a financiar los costes de campaña (que se incrementan en un $242 \%$ ) como en los destinados a las inversiones (que aumentan un $400 \%$ ) - y en el volumen de los créditos concedidos (alcanzan la cifra de casi 36 mil millones de reales, que equivalen a unos 12 millones de euros).

FIGURA I. Evolución del número de contratos y recursos del PRONAF (campaña e inversión) entre los años 1999 y 2007, Brasil

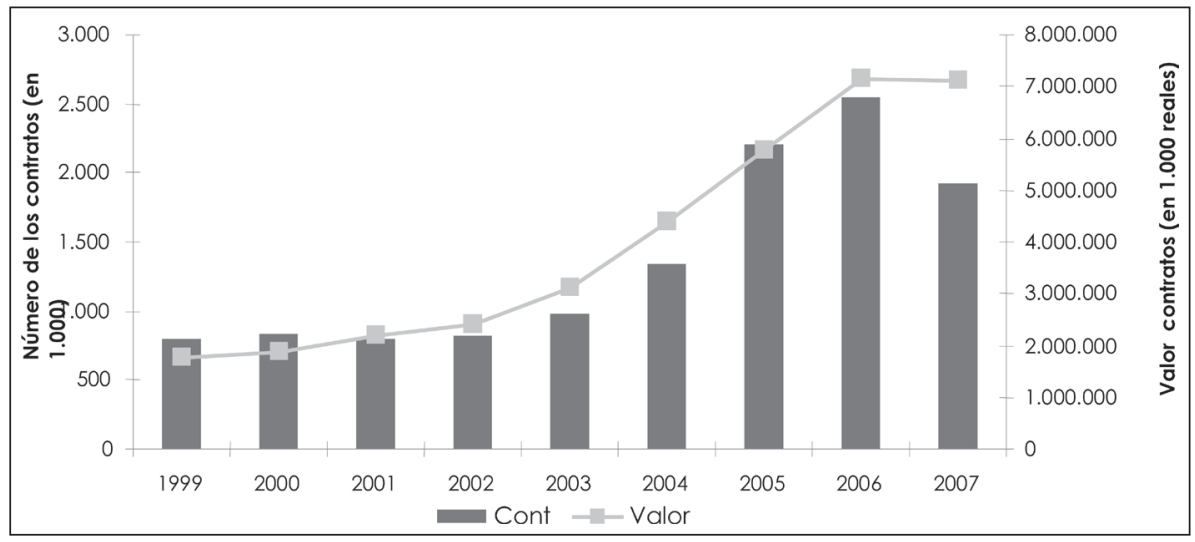

Fuente: Banco Central de Brasil (2008).

La financiación del PRONAF provenía fundamentalmente de fondos públicos -como el Fondo de Amparo al Trabajador (FAT) o los diversos fondos de desarrollo de las regiones Norte (FNO), Centro-Oeste (FCO) y Nordeste (FNE)-, además de la contribución realizada por la banca cooperativa y de los recursos obligatorios procedentes de las entidades privadas ${ }^{8}$. A ello, habría que unir los recursos procedentes de las operaciones oficiales de crédito con cargo al presupuesto general del Estado federal.

${ }^{8}$ El Banco Central de Brasil por medio del Manual do Crédito Rural (MCR) estableció una regla según la cual todos los bancos privados debían destinar determinados porcentajes de sus depósitos a la financiación de actividades agrícolas y ganaderas. 
Desde el comienzo del presente siglo XXI surgieron críticas al PRONAF, muchas de ellas denunciando la excesiva concentración de los recursos en la concesión de créditos para financiar las actividades vinculadas a los sistemas de integración vertical en el sector de la agricultura intensiva (como la producción de tabaco y la producción avícola y porcina). La crítica se agudizaba en el caso del tabaco, ya que se trataba de un sector controlado por las grandes empresas multinacionales, y cuya expansión se había hecho gracias a la venta masiva de insumos por la vía de la integración vertical, razones por las que, en opinión de estas posiciones críticas, no debían ser apoyadas con fondos públicos. El resultado de tales críticas fue retirar del programa los recursos procedentes del citado fondo FAT (Fondo de Amparo al Trabajador), lo que supuso una drástica disminución de los recursos destinados a este sector del tabaco, un sector que en 1997 concentraba la mitad de los contratos del PRONAF en los estados de Rio Grande do Sul y Santa Catarina, y en torno al 20\% en el conjunto del país (Abramovay y Veiga, 1999:30).

Estudios como el de Ricci et al (1997) mostraban que el 53\% de los agricultores del estado de Minas Gerais (región Sureste de Brasil) que contrataron créditos a través del PRONAF no lo habían hecho con anterioridad en un período de tiempo igual o superior a siete años, lo que indicaba la importancia que tenía el programa en el acceso al crédito por parte de grupos tradicionalmente excluidos.

Pero hay otros datos que deben ser señalados para comprender la magnitud de los efectos de esta política pública singular. Según los datos del último censo agrícola (1995-1996) de Brasil, existían a mediados de los años 90 cerca de 4,85 millones de explotaciones agrarias, que ocupaban 353 millones de hectáreas. De acuerdo con los datos del Incra Sade (Brasil, 2007), las explotaciones de carácter familiar correspondían a 4,13 millones unidades de producción (el 85,2\% del total) que acaparaban el $30,5 \%$ de la superficie agrícola total y generaban el $37,9 \%$ del valor bruto de la producción agrícola brasileña. En el año agrícola 2006-2007, la financiación de los costes de campaña a través del PRONAF alcanzó el número de 1,6 millones de contratos, lo que corresponde "grosso modo" a un porcentaje equivalente aproximadamente al $40 \%$ del universo potencial de beneficiarios.

Como afirma Presotto Nunes (2005), otros cambios importantes en la evolución del PRONAF fueron la disminución de los recursos financieros aportados por la banca privada, el incremento de los niveles de bonificación de los créditos y la inclusión de nuevas líneas de actuación destinadas a atender las demandas de nuevos grupos de beneficiarios (mujeres, jóvenes rurales, producción agroecológica, agroindustrias artesanales, explotación forestal,...). 
No obstante la importancia de los aspectos antes comentados, el principal problema que destacan los analistas del PRONAF ha sido la excesiva concentración regional de los recursos del programa en los estados meridionales (Rio Grande do Sul, Santa Catarina y Paraná). Como afirman Abramovay y Veiga (1999), en el año 1996 se concentró en esa región el 77\% de los contratos de crédito del PRONAF y el $64,7 \%$ del volumen de los créditos concedidos para la financiación de los costes de campaña, proporción que se redujo el año siguiente al $69 \%$ y $67 \%$, respectivamente, del crédito de campaña.

La Figura $\mathrm{n}^{\circ} 2$ muestra la evolución reciente del PRONAF desde el punto de vista de la distribución del número de contratos de crédito según las grandes regiones brasileñas. Puede observarse cómo la participación de los estados del Sur ha descendido a lo largo del período (pasando de concentrar aproximadamente el $60 \%$ de los contratos en el año 1999, a tan sólo el $28,5 \%$ en 2007), al tiempo que ha aumentado la participación de los estados del Nordeste (del 23,9\% al 49,9\% de los contratos en ese periodo).

\section{FIGURA 2. Evolución de la distribución porcentual del número de contratos del PRONAF (campaña e inversión) entre las regiones brasileñas entre los años 1999 y 2007}

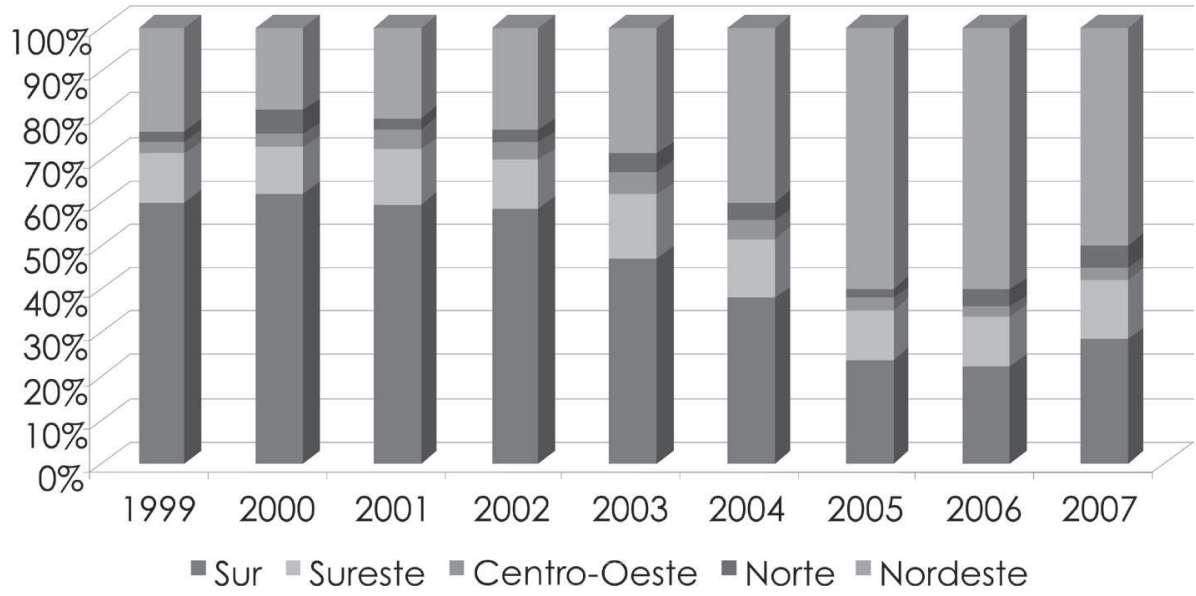

Fuente: Banco Central do Brasil (2008).

Sin embargo, cuando se considera la situación del PRONAF desde la perspectiva del volumen de los recursos aplicados, el protagonismo de los estados meridio- 
nales sigue siendo dominante. Como se muestra en la Figura $n^{\circ} 3$, esta región concentraba el 50,9\% de los recursos del programa en el año 1999, aunque en el último año analizado (2007) su participación descendió al 45,4\%. Los estados de la región Norte y Nordeste pasaron a concentrar en ese año 2007, el 6,7\% y $20,3 \%$, respectivamente, de los recursos totales del PRONAF.

\section{FIGURA 3. Evolución de la distribución porcentual del valor de los contratos del PRONAF (campaña e inversión) entre las regiones brasileñas entre los años 1999 y 2007}

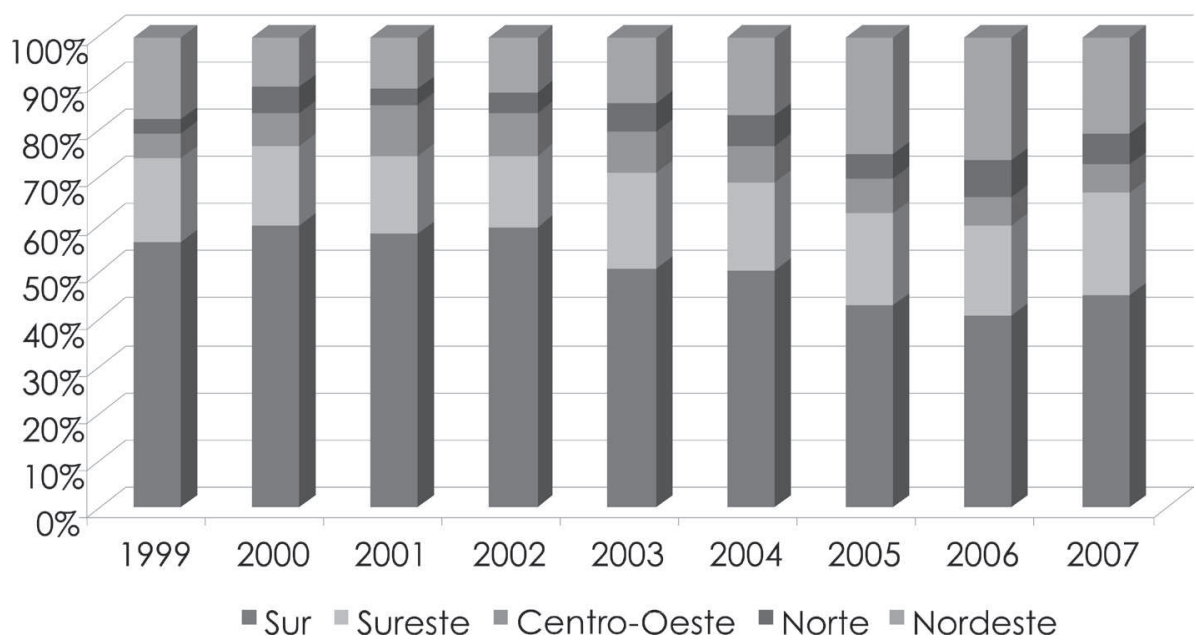

Fuente: Banco Central do Brasil (2008).

Para explicar esta situación hay que tener en cuenta que las regiones del Norte y el Nordeste son las más deprimidas de Brasil desde la perspectiva del desarrollo humano, debido a una serie de factores y problemas estructurales, entre los que cabe destacar los siguientes: deficientes infraestructuras productivas, elevado grado de concentración de la propiedad de la tierra, analfabetismo, bajo nivel de escolaridad de los agricultores y trabajadores rurales, y precariedad de los servicios prestados por los gobiernos de los estados, sobre todo en lo referente a las agencias de fomento, desarrollo y extensión rural. Ese contexto de las regiones Norte y Nordeste es también muy importante para comprender las diferencias que se exponen a continuación en lo que se refiere al incumplimiento de los contratos del PRONAF y al nivel de morosidad generada entre los agricultores beneficiarios del programa. 


\section{El incumplimiento de los contratos del PRONAF}

\section{I.Aspectos metodológicos y conceptuales del análisis}

Algunas aclaraciones iniciales son importantes para afrontar el análisis de los datos utilizados a partir de informaciones recogidas en veinticuatro instituciones financieras y referidas a operaciones consideradas como "activas" en la fecha del 31 de agosto de 2007. Bajo ese concepto de "operaciones activas" se incluyen los contratos realizados hasta el día 30 de junio de 2006 y que abarcan todo tipo de deudas enmarcadas en el capítulo "riesgo de la Unión", pero que todavía no habían sido tramitadas para su inclusión en la "deuda activa del Estado", ni contabilizadas totalmente como "perjuicio estatal".

Es con base en esa forma de clasificación que el Ministerio de Hacienda registra los datos sobre el incumplimiento de los contratos del PRONAF por parte de los agricultores beneficiarios. Según el Banco Central de Brasil, el Informe de dicho ministerio incluye los préstamos parciales o integrales de las deudas con vencimiento en 2007 y que fueron saldadas hasta la fecha del 31/12/2007. En dicho Informe se incluyen las operaciones de créditos de campaña y de inversión concedidos en el marco del PRONAF con vencimiento el año 2007 y que fueron objeto de aplazamiento hasta el 15 de febrero del 2008.

Por lo tanto, bajo el concepto de "incumplimiento de contratos de crédito" quedan incluidas las operaciones de crédito de campaña y de inversión en situación de impago y cuyos beneficiarios (los agricultores familiares y los campesinos asentados en las áreas de reforma agraria y demás programas de acceso a la tierra) no habían conseguido renegociar sus deudas con los bancos públicos o privados que gestionan dicho programa hasta el final del año fiscal de 2007.

El endeudamiento de los agricultores y campesinos ha instado al gobierno brasileño a poner en marcha acciones destinadas a la renegociación de las deudas morosas. Se trata de buscar soluciones para los casos de aquellos agricultores endeudados con los bancos, que no pueden afrontar el monto de la deuda, al igual que se hizo con los grandes agricultores permitiéndoles transformar activos líquidos y homogéneos (cuentas por cobrar) en títulos comercializables en el mercado de capitales, tema que escapa a los objetivos del presente artículo.

Pero el incumplimiento por parte de los agricultores del pago de las deudas contraídas a través del PRONAF debe ser analizado de forma tal que nos permita 
desvelar las causas que han generado esa situación de endeudamiento, situación que, como se verá a continuación, afecta a determinados grupos de agricultores y no al conjunto de la agricultura de tipo familiar.

\subsection{Naturaleza y alcance del incumplimiento de las deudas por los agricul- tores familiares}

En el decenio que abarca los años agrícolas 1998-1999 y 2007-2008 se firmaron 12,11 millones de contratos del PRONAF (créditos de campaña y de inversión), lo que representa aproximadamente $\mathbf{4 5}$ mil millones de reales. No obstante la magnitud global de las cifras, la tasa de incumplimiento es tan sólo del 2,5\% de los beneficiarios, si bien en los últimos años, tras la expansión del PRONAF (ya sea por el aumento del número de proyectos y del volumen de recursos, ya sea por haber alcanzado a regiones hasta entonces excluidas del programa) se observan fuertes indicios de crecimiento de la insolvencia en muchas familias beneficiarias de los créditos.

Los datos del Cuadro $n^{\circ} 1$ muestran la situación global de los contratos del PRONAF referidos a un conjunto equivalente a 2,14 millones de operaciones, que incluyen contratos de campaña e inversión para agricultores familiares, para colonos asentados en las áreas de la reforma agraria y para colonos asentados en el marco de otros programas de acceso a la propiedad de la tierra. Como se puede observar, tan sólo el 1,3\% de las operaciones se considera bajo el epígrafe "perjuicio al Estado", ascendiendo a aproximadamente 150 millones de reales. Por otra parte, el incumplimiento en los contratos llega al 28,9\%, que corresponde a 618 mil operaciones de crédito.

Bajo el calificativo de "incumplimiento" hay un amplio abanico de situaciones, cuya diversidad procuraremos ordenar en las siguientes líneas. Cada una de esas situaciones es resultante de ciertas condiciones y circunstancias singulares que exigen actuaciones específicas por parte del gobierno en aras de afrontar con realismo y eficacia la creciente insolvencia de las familias beneficiarias de los contratos de crédito del PRONAF.

Los contratos de créditos de inversión firmados por los agricultores familiares vinculados a las líneas $C$, D y E se financian con la aportación de recursos de carácter público (ya sea procedentes del ya citado fondo FAT, ya sea de los llamados Fondos Constitucionales). En estas tres líneas quedan incluidos los agricultores familiares con rentas más altas, siendo éstas las líneas que en su conjunto concentran la mayor parte de los créditos del PRONAF. 
CUADRO I. Distribución de los contratos de financiación del PRONAF en operaciones de costes e inversión, según la condición de cumplimiento, valor promedio y total de la deuda

\begin{tabular}{|l|r|r|c|r|}
\hline \multicolumn{1}{|c|}{ Situación } & $\begin{array}{c}\text { Número de } \\
\text { contratos }\end{array}$ & $\%$ & $\begin{array}{c}\text { Valor prome- } \\
\text { dio (R\$) }\end{array}$ & $\begin{array}{c}\text { Valor total de la } \\
\text { Deuda (R\$) }\end{array}$ \\
\hline Cumplimiento & 1.494 .613 & 69,8 & 6.807 & 10.173 .992 .597 \\
\hline Incumplimiento & 618.092 & 28,9 & 4.992 & 3.085 .702 .181 \\
\hline Perjuicio & 28.760 & 1,3 & 8.935 & 150.093 .880 \\
\hline Total & 2.141 .465 & 100,0 & 6.312 & 13.409 .788 .658 \\
\hline
\end{tabular}

Fuente: Ministerio de Hacienda (2008).

Como señala Guanziroli (2007:308), este sector más acomodado de la producción familiar brasileña, concentró el 74\% de los recursos del PRONAF en 2004, situación que se ha mantenido en el período subsiguiente. En el año 2006-2007, los agricultores con rentas más bajas (beneficiarios de las líneas $A, A / C$ y $B$ ) concentraron tan sólo el $30,5 \%$ de las operaciones totales del programa y el $14,0 \%$ del montante de crédito. En el extremo opuesto, los estratos de rentas más elevadas (C, D, E) absorbieron en ese año el $69,5 \%$ de las operaciones y el $86,1 \%$ de los recursos globales del PRONAF (algo inferior al periodo antes señalado).

CUADRO 2. Distribución de los contratos de inversión del PRONAF en operaciones de inversión (líneas C, D, E), según situación de incumplimiento las regiones de Brasil

\begin{tabular}{|l|r|c|c|c|c|r|r|c|}
\hline \multirow{2}{*}{ Región } & \multicolumn{2}{|c|}{ Cumplimiento } & \multicolumn{2}{|c|}{ Incumplimiento } & \multicolumn{2}{c|}{ Perjuicio } & \multicolumn{2}{c|}{ Total } \\
\cline { 2 - 9 } & $\begin{array}{c}\mathbf{N}^{\circ} \text { de } \\
\text { contratos }\end{array}$ & $\%$ & $\begin{array}{c}\mathbf{N}^{\circ} \text { de } \\
\text { contratos }\end{array}$ & $\%$ & $\begin{array}{c}\mathbf{N}^{\circ} \text { de } \\
\text { contratos }\end{array}$ & $\%$ & $\begin{array}{c}\mathbf{N}^{\circ} \text { de } \\
\text { contratos }\end{array}$ & $\%$ \\
\hline NE & 170.579 & 76,3 & 52.888 & 23,7 & - & - & 223.467 & 100,0 \\
\hline NO & 110.580 & 86,5 & 2.160 & 1,7 & 15.056 & 11,8 & 127.796 & 100,0 \\
\hline CO & 29.840 & 98,2 & 536 & 1,8 & - & - & 30.376 & 100,0 \\
\hline SE & 68.461 & 94,9 & 3.654 & 5,1 & - & - & 72.115 & 100,0 \\
\hline S & 209.299 & 98,8 & 2.624 & 1,2 & - & - & 211.923 & 100,0 \\
\hline Brasil & 588.759 & 88,4 & 61.862 & 9,3 & 15.056 & 2,3 & 665.677 & 100,0 \\
\hline
\end{tabular}

Fuente: Ministerio de Hacienda (2008). 
Los datos del Cuadro 2 indican que, en su conjunto, estas tres líneas de financiación suman 665.677 contratos, lo que supone una deuda total de 6,24 mil millones de reales. De todas las regiones brasileñas, la región Nordeste presenta el mayor porcentaje $(85,5 \%)$ de incumplimiento en la devolución de los créditos de inversión del PRONAF (52.888 contratos) entre todas las regiones del país.

En la Región Norte, el incumplimiento en los contratos de inversión alcanza 2.160 operaciones, pero, como indica el Cuadro 2, en esa región se registró un total de 15.056 operaciones clasificadas con el calificativo de "perjuicio al Estado" y que están vinculadas sobre todo a los recursos procedentes del fondo FNO. En el extremo opuesto, las regiones Centro-Oeste, Sureste y Sur presentan niveles reducidos de incumplimiento $(1,8 \%, 5,1 \%$ y $1,2 \%$, respectivamente).

Hay otro aspecto que debe ser analizado en lo que afecta a los créditos de inversión del PRONAF, y es el relativo a los campesinos asentados en las áreas de la reforma agraria y de otros programas de acceso a la tierra (línea $A$ del programa, financiada con recursos del Presupuesto General de la República y de los Fondos Constitucionales, por lo que el riesgo se transfiere íntegramente al Estado brasileño).

En efecto, como muestra el Cuadro 3, las operaciones en esa línea A suman 292.714 contratos y un saldo deudor que asciende a 2,6 mil millones de reales, según las fuentes consultadas. El incumplimiento en esas operaciones llega al 23,5\%, y las operaciones calificadas como "perjuicio al Estado" representan el 1,2\% de los contratos. Sin embargo, es en la línea B del PRONAF donde se encuentra el más alto grado de incumplimiento $(40,3 \%)$ en los contratos, línea que, como se ha señalado, incluye a los agricultores familiares con los más bajos niveles de ingresos económicos.

El gobierno brasileño estableció un incentivo destinado a los beneficiarios que pagasen sus deudas en la fecha indicada en el contrato (descuento de $25 \%$ ), con objeto de crear una nueva mentalidad entre los agricultores respecto al uso de los créditos con fines productivos. No se trata sólo de asegurar el pago puntual de las deudas, sino fomentar una "cultura del cumplimiento". Sin embargo, a pesar de que el volumen de la deuda no pagada no es demasiado alto en términos globales (275 millones de reales), lo cierto es que, debido al bajo valor de los contratos (1.058 reales/contrato como media), el porcentaje de incumplimiento es muy elevado.

El conjunto formado por las líneas $C, D$ y E concentra la mayor parte de los créditos de inversión del PRONAF. En ese caso, el vínculo financiero es con el fondo FAT y 
con los Fondos Constitucionales, cargando, por tanto, el riesgo sobre los agentes financieros, a excepción de los casos que afectan a recursos procedentes de los fondos FNE y FNO, donde se comparten los riesgos.

En el Cuadro 3 puede verse que los contratos de la línea $C$ presentan una tasa de incumplimiento relativamente baja $(8,1 \%)$, así como de operaciones calificadas "en perjuicio" $(0,7 \%)$. Por otra parte, la línea D posee la más alta tasa de incumplimiento $(10,7 \%)$ en ese subgrupo de agricultores con rentas anuales más elevadas, así como de operaciones calificadas en "perjuicio" $(3,5 \%)$

\section{CUADRO 3. Distribución de los contratos del PRONAF en operaciones de inversión en las líneas A, B, C, D, E, según situación de cumplimiento/incumplimiento y perjuicio}

\begin{tabular}{|c|r|r|r|r|r|r|r|}
\hline \multirow{2}{*}{ Línea } & \multicolumn{2}{|c|}{ Cumplimiento } & \multicolumn{2}{c|}{ Incumplimiento } & \multicolumn{2}{c|}{ Perjuicio } & \multicolumn{1}{c|}{ Total } \\
\cline { 2 - 9 } & $\begin{array}{c}\mathbf{N}^{\circ} \text { de } \\
\text { Contratos }\end{array}$ & $\%$ & $\begin{array}{c}\mathbf{N}^{\circ} \text { de } \\
\text { Contratos }\end{array}$ & $\%$ & $\begin{array}{c}\mathbf{N}^{\circ} \text { de } \\
\text { Contratos }\end{array}$ & $\%$ & $\begin{array}{c}\mathbf{N}^{\circ} \text { de } \\
\text { Contratos }\end{array}$ \\
\hline A & 220.505 & 75,3 & 68.696 & 23,5 & 3.513 & 1,2 & 292.714 \\
\hline B & 328.898 & 59,6 & 222.310 & 40,3 & 230 & 0,0 & 551.438 \\
\hline C & 240.466 & 91,2 & 21.365 & 8,1 & 1.758 & 0,7 & 263.589 \\
\hline D & 324.144 & 85,8 & 40.410 & 10,7 & 13.296 & 3,5 & 377.850 \\
\hline E & 24.149 & 99,6 & 87 & 0,4 & 2 & 0,0 & 24.238 \\
\hline Brasil & 1.138 .162 & - & 352.868 & - & 18.799 & - & 1.509 .829 \\
\hline
\end{tabular}

Fuente: Ministerio de Hacienda (2008).

Las causas para explicar el aumento de las tasas de incumplimiento del PRONAF deben ser buscadas, sobre todo, en la expansión del programa hacia regiones en las que nunca los agricultores habían tenido la oportunidad de acceder a fondos públicos de financiación. Eso ha ocurrido no sólo en el caso de los asentados en las áreas de reforma agraria (línea A) y de los agricultores con explotaciones con rentas muy bajas (línea $B$ ), sino también en el caso de los que tienen rentas más altas (líneas $C$ y D). Es decir, el incumplimiento creció conforme el programa se extendió a las zonas más deprimidas de Brasil, expansión impensable unos años atrás.

En la línea E del PRONAF, el incumplimiento es prácticamente nulo. Hay en ese grupo una fuerte participación de los agricultores familiares de los estados meri- 
dionales de Brasil, que son los que poseen un alto nivel de profesionalización y una mayor integración en los mercados (internos y, sobre todo, externos).

Llama la atención el hecho de que si se considera el conjunto formado por las líneas $C, D$ y E, la participación del Nordeste en el incumplimiento de los contratos del PRONAF asciende al 85,5\%. Además, dicha región es responsable de casi el $80 \%$ de los 99,6 millones reales en contratos vencidos en Brasil.

Resulta que es precisamente en las zonas septentrionales del país (estados del Norte y Nordeste) donde los campesinos se enfrentan a una serie de dificultades de carácter políitico, técnico y social. Sin embargo, hay un aspecto crucial para explicar dicho escenario, aspecto que tiene que ver con el grado de integración de la agricultura en los mercados. Así, mientras en los estados del Sur los agricultores están fuertemente integrados en los mercados, en los del Norte y Nordeste existen estructuras socio-productivas muy precarias que, a menudo, son controladas por las oligarquías locales.

El estudio realizado por FAO/INCRA (1994) basado en los datos del último censo agrícola (1995-1996), estableció una metodología con la que es posible analizar las distintas regiones brasileñas, según grados de integración en los mercados. En efecto, como muestra el Cuadro 4, si en el Centro-Oeste, Sureste y Sur de Brasil el porcentaje de explotaciones familiares poco integradas en los mercados equivale a, respectivamente, el $28,2 \%$, el $37,2 \%$ y el $32,7 \%$, ese mismo dato para las regiones Norte y Nordeste asciende a $51,4 \%$ y $51,1 \%$.

\section{CUADRO 4. Distribución porcentual de las explotaciones familiares según las grandes regiones brasileñas y grado de integración en los mercados}

\begin{tabular}{|l|c|c|c|c|}
\hline \multirow{2}{*}{ Regiones } & \multicolumn{4}{|c|}{ Grado de integración en los mercados } \\
\cline { 2 - 5 } & Muy integrado & Integrado & Poco integrado & Sin informar \\
\hline Norte & 15,5 & 31,4 & 51,4 & 1,7 \\
\hline Nordeste & 15,1 & 31,9 & 51,1 & 1,9 \\
\hline Centro-Oeste & 27,8 & 39,9 & 28,2 & 4,1 \\
\hline Sureste & 29,4 & 29,2 & 37,2 & 4,2 \\
\hline Sur & 21,9 & 43,8 & 32,7 & 1,6 \\
\hline
\end{tabular}

Fuente: Incra - Sade (2007). 
Cabe finalizar la exposición sobre el incumplimiento de los contratos del PRONAF mostrando algunos datos relativos al crédito destinado a financiar los costes de campaña. Los datos del Cuadro 5 indican algunas diferencias en relación al anteriormente expuesto sobre el crédito de inversión. Las más altas tasas de incumplimiento se encuentran entre agricultores encuadrados en las líneas $A$ y $A / C$ (crédito de instalación para los asentados en las tierras de reforma agraria), representando el $72,2 \%$ y el $75,4 \%$, respectivamente. En tales operaciones el riesgo recae sobre el presupuesto de la República y los ya citados Fondos Constitucionales. Estos datos parecen reflejar lo que otros estudios ya habían subrayado sobre la situación precaria de muchas familias asentadas a través de los programas de acceso a la tierra en Brasil (como es el caso del Banco de la Tierra), pero sobre todo en los proyectos de reforma agraria.

Los contratos de la línea $C$ presentan un porcentaje de incumplimiento del $27,8 \%$ en esa modalidad de crédito (coste de campaña). Sin embargo, el 70\% del incumplimiento está ubicado en los estados del Nordeste, mientras que en los del Sur ese mismo indicador llega a un escaso 10\%. Los estados del Norte concentran tan sólo el 8,5\% de las operaciones de crédito de campaña, pero esa parte de Brasil es responsable del $99 \%$ de los contratos clasificados como de "perjuicio a la Unión".

CUADRO 5. Distribución de los contratos del PRONAF en operaciones de coste de la producción según las líneas (C, D, E, A e A/C) y grados de incumplimiento

\begin{tabular}{|c|c|c|c|c|c|c|c|}
\hline \multirow[b]{2}{*}{ Línea } & \multicolumn{2}{|c|}{ Cumplimiento } & \multicolumn{2}{|c|}{ Incumplimiento } & \multicolumn{2}{|c|}{ Perjuicio } & \multirow{2}{*}{$\begin{array}{l}\text { Total de } \\
\text { Contratos }\end{array}$} \\
\hline & $\begin{array}{c}\mathrm{N}^{\circ} \text { de } \\
\text { Contratos }\end{array}$ & $\%$ & $\begin{array}{c}\mathrm{N}^{\circ} \text { de } \\
\text { Contratos }\end{array}$ & $\%$ & $\begin{array}{c}\mathrm{N}^{\circ} \text { de } \\
\text { Contratos }\end{array}$ & $\%$ & \\
\hline A & 10.094 & 27,1 & 26.855 & 72,2 & 247 & 0,7 & 37.196 \\
\hline $\mathrm{A} / \mathrm{C}$ & 7.446 & 22,7 & 24.772 & 75,4 & 646 & 2,0 & 32.864 \\
\hline$C$ & 167.089 & 71,9 & 64.627 & 27,8 & 748 & 0,3 & 232.464 \\
\hline$D$ & 58.762 & 61,8 & 35.024 & 36,8 & 1.301 & 1,4 & 95.087 \\
\hline$E$ & 13.144 & 93,3 & 935 & 6,6 & 2 & 0,0 & 14.081 \\
\hline Brasil & 256.535 & - & 152.213 & - & 2.944 & - & 411.692 \\
\hline
\end{tabular}

Fuente: Ministerio de Hacienda (2008).

Hay un conjunto de factores que explican el grado de incumplimiento en los contratos del PRONAF. La falta de asistencia técnica a los agricultores familiares, particu- 
larmente en el caso de los asentados de la reforma agraria y de los programas de acceso a la tierra, es el factor más destacable, además de otros aspectos tales como el bajo nivel de escolaridad y el analfabetismo de los productores, así como la carencia de infraestructuras de transporte y comercialización, y las grandes dificultades de acceso a los mercados. Dicha dinámica es recurrente en todo el territorio nacional, pero afecta de modo muy especial a los agricultores residentes en las zonas del Norte y Nordeste de Brasil, que son precisamente donde crece el número de asentamientos de reforma agraria.

\section{Conclusiones}

La experiencia del Banco Grameen en Bangladesh ha propiciado que a su creador (Muhammad Yunus) se le concediera en el año 2006 el Premio Nobel de la Paz. Él nos ha enseñado la importancia del microcrédito para la inclusión social y la erradicación de la pobreza en muchas zonas de ese país. Su experiencia sirvió para romper con el mito de que los pobres no son buenos pagadores y de que es posible combatir la desigualdad de una forma original y emancipatoria. Las ideas de Yunus coinciden con los planteamientos de Amartya Sen (2002), otro pensador asiático y Nobel de Economía (1998), para quien el desarrollo supone la ampliación de las libertades sustantivas (enseñanza, salud,...) en las que se incluye el acceso al crédito para emprender proyectos de desarrollo.

Coincidimos con tales premisas en términos globales, pero el caso de Brasil nos indica que las políticas basadas exclusivamente en la concesión de créditos bonificados no son suficientes para superar los obstáculos que afectan a una proporción significativa de pequeños agricultores familiares. No hay duda de que el PRONAF es resultado de las reivindicaciones de los movimientos sociales rurales de Brasil, y que su expansión hacia áreas rurales marcadas históricamente por la desigualdad social debe ser calificada de conquista incuestionable. Pero el PRONAF no es suficiente para modificar las estructuras sociales y económicas arcaicas que aún persisten en ciertas áreas de un país tan inmenso como Brasil, particularmente en sus regiones del Norte y Nordeste. Es en esas regiones donde las tasas de incumplimiento de los contratos (tanto en los créditos de campaña, como en los de inversión) y, por tanto, la morosidad de los pequeños agricultores, han crecido muy por encima de lo ocurrido entre los agricultores de las regiones del Sur, Sureste y Centro-Oeste.

Bien es cierto que en los estados del Sur y Sureste (particularmente en los estados meridionales) la agricultura familiar se enfrenta también a dificultades similares a 
las que afectan a los agricultores de otras partes del mundo, pero lo fundamental es que en esos estados meridionales de Brasil existe un mayor nivel de profesionalización de los agricultores, una relación más intensa con los mercados y, sobre todo, una actuación más eficiente de los servicios e instituciones públicas. En esas regiones de Brasil existe, además, un consenso a la hora de comprender que el PRONAF necesita de la extensión rural para tener éxito, en la misma medida en que la extensión rural necesita del PRONAF.

La desactivación de la política de extensión rural en los estados del Norte y Nordeste asestó un duro golpe a la reproducción social y económica de muchas unidades productivas agrarias, en especial en los asentamientos de la reforma agraria. Las razones de las altas tasas de incumplimiento de los contratos del PRONAF en esas regiones deben ser buscadas en la precariedad en que se hallan inmersos los programas de acceso a la tierra desde la perspectiva de las infraestructuras productivas y de la ausencia de un adecuado sistema de extensión rural.

Cabe aquí retomar las grandes cuestiones que orientaron la investigación que ha sido la base de este artículo. En ese sentido, cabe señalar cómo el enfoque utilizado a la hora de analizar el PRONAF brasileño ha servido para mostrar que las más altas tasas de incumplimiento de los contratos por parte de los pequeños agricultores familiares se encuentran entre los asentados de la reforma agraria y de otros programas de acceso a la tierra. Sin embargo, los datos reflejan que el incumplimiento se concentra en términos espaciales y entre los productores que presentan rentas más bajas y bajos niveles de integración de los mercados. En efecto, la expansión del PRONAF hacia regiones más deprimidas de Brasil ha ido acompañada de un aumento en las tasas de incumplimiento de los contratos. Los agricultores de los estados del Sur y Sureste brasileño presentan unos reducidos niveles de incumplimiento, al tiempo que un mayor grado de integración en los mercados y de profesionalización de sus actividades, además de rentas más elevadas.

Estas consideraciones son especialmente importantes y convergen hacia lo que Marsden (1998) denomina la "tercera vía" del desarrollo rural, en el sentido de procurar la integración de una economía orientada al mercado con una política de redistribución social. Es imperativo avanzar en la adopción de un amplio arsenal de políticas que articulen el crédito rural con otras medidas de carácter estructural. En las actuales circunstancias, el PRONAF no cumple con el compromiso de convertirse en una verdadera política de desarrollo rural/territorial, debido precisamente a que se ha limitado a ser una simple política de crédito agrícola. 
Pero para que se produzca la integración entre políticas de crédito y políticas de estructuras hay un largo camino que andar, y ello implica superar el sesgo agrarista que acompaña desde sus orígenes a las políticas agrarias de tipo sectorial. Ello requiere una apuesta por los nuevos enfoques integrales del desarrollo rural, unos enfoques centrados en la diversificación productiva y en la multifuncionalidad de la agricultura. Otro aspecto importante que debe ser tenido en cuenta es el relacionado con la ampliación y fortalecimiento de los sistemas de crédito cooperativo, cuyos impactos son muy significativos para reducir los costes de transacción de los proyectos. Desde nuestro punto de vista, es fundamental profundizar en el perfeccionamiento del PRONAF, ya que es, sin duda, una de las más interesantes políticas públicas puestas en marcha en la reciente historia brasileña.

\section{Referencias bibliográficas}

Abramovay, R. y Veiga, J. E. (1999) "Novas instituições para o desenvolvimento rural: o caso do Programa Nacional de Fortalecimento da Agricultura Familiar (PRONAF)", Texto para Discussão, n 641, Brasília, FIPE/IPEA 07/97.

Baudel Wanderley, M. N.(1999) "Raízes históricas do campesinato brasileiro", en J. C. TEDESCO (coord.) Agricultura familiar: realidades e perspectivas, Passo Fundo, pp. 23-56.

BELKK, W. (2000) "Pronaf: avaliação da operacionalização do programa", en J. Graziano da Silva y C. Campanhola (coords.), O novo rural brasileiro: políticas públicas, vol.4, EMBRAPA Meio Ambiente, Jaguariúna/SP, pp.93-115.

BITENCOURT, G.A. (2003) Abrindo a caixa-preta: o financiamento da agricultura familiar no Brasil, Dissertação (Mestrado em Desenvolvimento Econômico, Espaço e Meio Ambiente), Campinas, Universidade Estadual de Campinas.

Domingos Neto, M. (2004) "O Novo Mundo Rural", em M. Dias Martins (coord.), O Banco Mundial: ofensiva e resistência neoliberal na América Latina, África e Ásia, São Paulo, Viramundo, pp.27-39.

FAO/INCRA (1994) Diretrizes de política agrária e desenvolvimento sustentável para a pequena produção familiar, Brasília, INCRA.

Graziano da Silva, J. (1982) A modernização dolorosa, Rio de Janeiro, Zahar Editores. 
GUANZIROLI, C.E. (2007) “PRONAF, dez anos depois: resultados e perspectivas para o desenvolvimento rural", Revista de Economia e Sociologia Rural, Rio de Janeiro, vol. 45, n 02, pp.301-328.

Hervieu, B. (1996) Los Campos del Futuro, Madrid, MAPA.

LEITE, S. (2004) "Autoconsumo y sustentabilidad en la agricultura familiar: una aproximación a la experiencia brasileña", en W. BEIK (COORD.), Políticas de seguridad alimentaria y nutrición en América Latina, São Paulo, Hucitec, pp.123-164.

MARSDEN, T. (1998): "New Rural Territories: Regulating the Differentiated Rural Spaces", Journal of Rural Studies, vol. 14, n³, pp.107-117.

Ministério do Desenvolvimento, Indústria e Comércio Exterior, Banco Nacional de Desenvolvimento EConômico e Social - BNDES (2008) Programa Nacional de Fortalecimento da Agricultura Familiar - PRONAF, Documento disponible em <http:// www.bndes.gov.br/espanol/pronaf es.asp> Aceso Em Noviembre 2008.

Ministério do Desenvolvimento Agrário. Instituto Nacional de ColonizaÇão e Reforma AGRÁRIA - INCRA/SADE. (2007) Banco de dados da agricultura familiar, Documento disponible en <http://www.incra.gov.br/sade/default.asp> Acceso en Abril del 2007.

Ministerio da Fazenda (Secretaria de Politica Economica) (2008) Levantamento das operações de crédito rural do pronaf, procera e crédito fundiário, Documento disponible en <http:// www.pronaf.gov.br/dater/index.php?.ctuid=16269\&sccid=104> Aceso en Junio 2008.

Pereira Bergamasco, S.M. (1993) "Família e trabalho rural no Brasil e no Estado de São Paulo", Informações Econômicas, São Paulo, vol. 23, pp. 1-58, pp. 7-16.

Presotto Nunes, S. (2005) "Pronaf: dez anos de existência", Boletim do Deser, ${ }^{\circ}$ 145, agosto, pp.9-19.

Programa das Nações Unidas para o Desenvolvimento, PNUD-Brasil (2005) Ranking do IDH dos Estados em 2005, Documento disponible em <http://www.pnud.org. $\mathrm{br} /$ pobreza_desigualdade/reportagens/index.php?id01=3039\&lay=pde $>$ Acceso en Noviembre 2008. 
Ramos, E. y Delgado, Ma M. (2002) "Nuevas formas de institucionalidad y su influencia en el desarrollo de las áreas rurales europeas", Información Comercial Española, n 803, pp. 91-104.

SAcco dos Anjos, F. (2001) "Pluriactividad y desarrollo rural en el sur de Brasil", Revista Internacional de Sociología, vol. 28, Madrid, Consejo Superior de Investigaciones Científicas, pp.

RIcCI, R. et all. (1997) Relatório da pesquisa de análise da execução do Programa Nacional de Fortalecimento da Agricultura Familiar (PRONAF) em Minas Gerais, Belo Horizonte, Lumen/Instituto de Pesquisas-PUC/MG.

Sacco dos Anjos, F.; Velleda Caldas, N.; Novo da Silva, F. y Moraes Bernardi, L. (2007) "Estudo sobre a Situação socioeconômica das famílias beneficiadas", Revista Redes, vol. 12, n², pp. 234-256.

SEN, A. (2002) Desenvolvimento como liberdade, São Paulo,Companhia das Letras. 